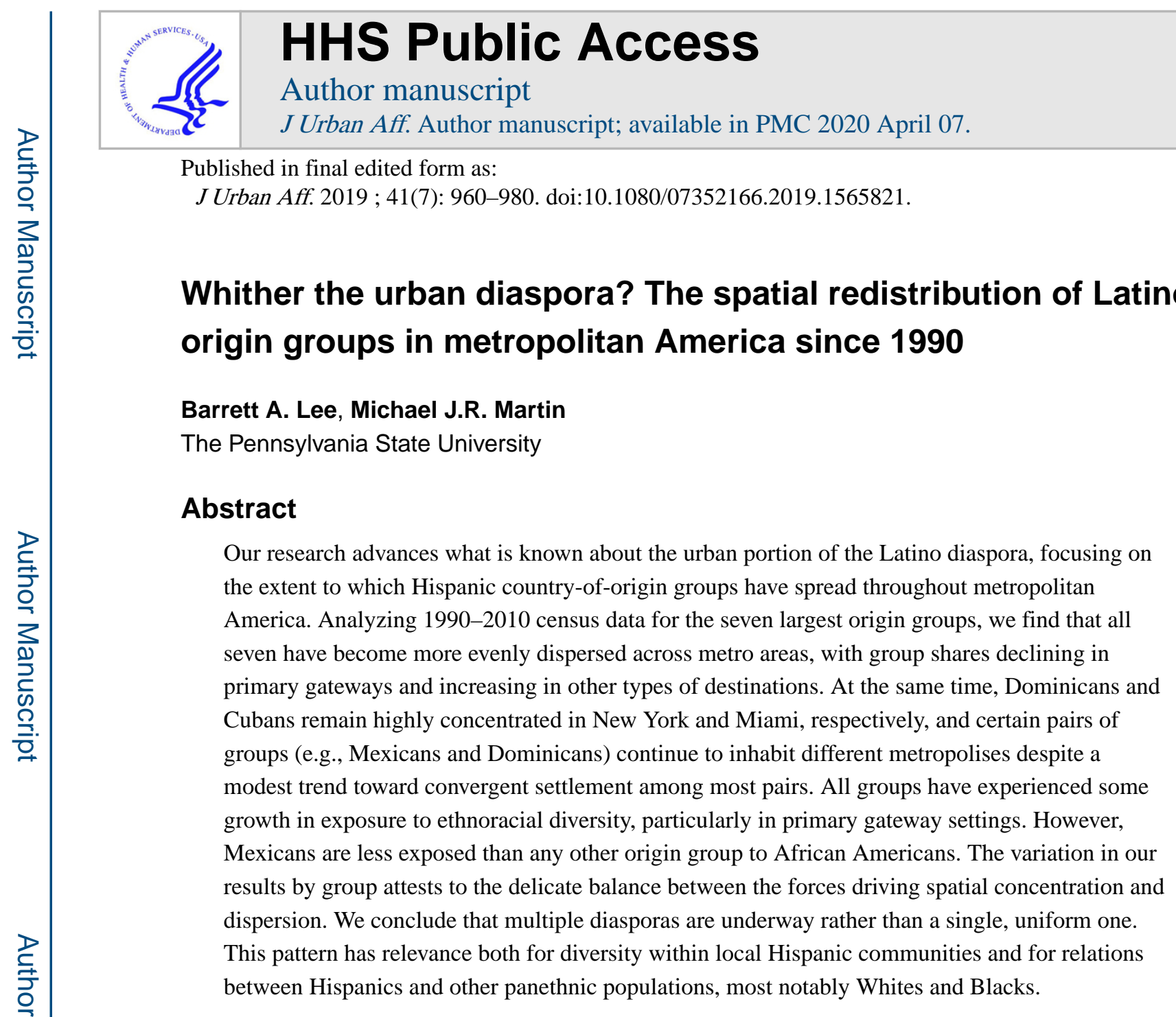

\title{
Introduction
}

The increasing ethnoracial diversity of the United States has profound implications for politics, the economy, education, social relations, and other domains of life (see, e.g., Bean \& Stevens, 2003; Frey, 2015; Lichter, 2013; Putnam, 2007). Since 1980 Latino and Asian shares of the national population have tripled in size while the proportion of Whites has declined from four-fifths to less than two-thirds (Lee et al., 2012). The trend toward a more equally-sliced ethnoracial "pie"-i.e., toward greater diversity—can be observed across all regions and states. Despite this pervasiveness, significant variation occurs in the magnitude of diversity and its pace of change. Differences among metropolitan areas are especially striking (Lee et al., 2014; Wright et al., 2014).

Such differences reflect the evolving geography of Hispanic and Asian settlement. As a general rule, where these two panethnic populations grow, so does the diversity of the metro area. We examine metropolitan Hispanics ${ }^{1}$ in part because of their sheer number. Of the 50.5

Contact author: Barrett A. Lee, bal6@psu.edu, Department of Sociology and Population Research Institute, Penn State University, 614 Oswald Tower, University Park, PA 16802.

1.We use the terms Hispanic and Latino interchangeably, in keeping with common practice. 
million Hispanics counted in the 2010 census, 46.7 million (or 92\%) live in metro areas (Wilson et al., 2012). For comparison's sake, the metropolitan Hispanic population exceeds the entire Black population (metro and nonmetro) by several million and is three times larger than the entire Asian population (Wilson et al., 2012). Our interest in metropolitan Latinos is also piqued by their long history of concentration in a handful of immigrant gateways, including Los Angeles, New York, Miami, and Chicago (Alberts, 2006; Foner, 2013; InnisJimenez, 2013; Sabagh \& Bozorgmehr, 2003). The impact of Latinos on these gateways is visible in residential enclaves (or barrios) and in distinctive cultural practices and institutions (e.g., Spanish language use, ethnic restaurants and grocery stores). Major gateways tend to be sites of broader civic engagement as well, with more Hispanics than elsewhere elected to local political office, serving on school boards, and attaining prominence in business and professional circles (NALEO Educational Fund, 2016; Ochoa, 2004; Vallejo, 2012).

Rather than take a high degree of gateway concentration for granted, we consider seriously the claim that a new stage in the Latino diaspora has begun in the U.S. (Arreola, 2004b; Tienda \& Fuentes, 2014; Wortham et al., 2002; Zuniga \& Hernandez-Leon, 2005). Evidence for the post-1990 period suggests that Hispanics are increasingly found in nontraditional or secondary destinations, not only in major gateways. Some of these destinations are outside of metropolitan areas. Indeed, Hispanic movement to small towns and rural settings has attracted substantial research coverage in recent years (Lichter, 2012; Marrow, 2011; Massey, 2008; Sharp \& Lee, 2017; Zuniga \& Hernandez-Leon, 2005). Our focus here is on the urban portion of the diaspora, specifically the redistribution of Hispanic country-oforigin groups (such as Mexicans or Cubans) within the metropolitan settlement system. We address three descriptive research questions about the issue:

1. To what extent have Hispanic origin groups become more spatially dispersed throughout metropolitan America?

2. Are different origin groups converging on the same set of metro areas or living in largely separate ones?

3. How, if at all, has the exposure of group members to ethnoracial diversity changed over time?

For all three questions, we define origin groups in expansive fashion, imposing no restrictions by nativity or generational status. ${ }^{2}$ Our answers to the questions also rest on a broad definition of dispersion, equating it with the shift of Latino populations toward a more complex, even distribution across all metro areas. There is a temptation to assume that the process is driven mainly by immigration and domestic migration flows, which channel more Hispanics to some metropolitan settings than others. Yet the Hispanic population also 'spreads out' through differences among areas in the excess of births over deaths, or natural increase (Johnson \& Lichter, 2008, 2016). Regardless of the demographic mechanisms

\footnotetext{
2. The practical reason for employing such a definition is that the census summary files used in our analysis do not report nativity or generation for Latino origin groups. Moreover, perceptions of shared physical attributes (like skin tone, body type, or facial features), ancestry, and cultural traditions are arguably more central to how "outsiders" (non-Latinos) view these groups (Cornell \& Hartmann, 1998).
} 
involved, we contend that the nature and ramifications of Latino metropolitan dispersion are important but remain somewhat unclear.

The importance of dispersion lies in its potential consequences. Reviews of existing research indicate that the social and economic outcomes for Latinos who opt for nontraditional metropolitan destinations may be positive, negative, or both (Tienda \& Fuentes, 2014; Waters \& Jimenez, 2005; Waters \& Pineau, 2015). Latino newcomers in turn can influence these destinations, stimulating community growth while straining local services and institutions that are unprepared to meet the needs of immigrant-rich groups from unfamiliar backgrounds. The arrival of Latinos also adds a new dynamic to intergroup relations, especially in southern metro areas long dominated by a Black-White color line (McClain et al., 2006; McDermott, 2011). The mixed empirical record about the consequences of dispersion is partly a function of the case study nature of scholarship on emerging Hispanic destinations (Arreola, 2004a; Flippen \& Parrado, 2012; Jones, 2008; Singer et al., 2008; Winders, 2013). Taken together, the case studies highlight significant variation in selected local contexts of reception. They are not designed, however, to yield general conclusions that pertain to all metro areas nationwide.

We pursue a more geographically comprehensive investigation of the Latino metropolitan diaspora, enriching it with attention to a critical but often overlooked detail. Much work on the topic still treats Hispanics in monolithic or panethnic fashion (e.g., Frey, 2015; Lichter \& Johnson, 2009; Suro \& Singer, 2003). Given the amount of socioeconomic and cultural variation among Hispanics with different Latin American and Caribbean roots (Logan and Turner, 2013; Rumbaut, 2006), unpacking the Hispanic panethnic population into specific country-of-origin groups strikes us as essential. Thus, our analysis describes the location and redistribution of the seven largest origin groups-Mexicans, Puerto Ricans, ${ }^{3}$ Cubans, Dominicans, Salvadorans, Guatemalans, and Colombians-across 363 metro areas in the United States from 1990 through 2010. This analysis encompasses not only secondary metropolitan destinations but also major established gateways, which continue to attract and retain millions of Latino residents. The next sections of the paper review some of the forces responsible for dispersing Latinos throughout the metropolitan settlement system and other forces, operating simultaneously, that are believed to promote concentration in a few primary gateways. We also discuss the implications of both sets of forces for group members' exposure to ethnoracial diversity and their applicability to specific origin groups.

\section{Background Forces of dispersion}

The contemporary diaspora combines the redistribution or dispersion of Latinos throughout metropolitan America with a relative decline in their concentration in established gateways such as Los Angeles and New York. To date, several investigations have reported some version of this pattern for the Hispanic population as a whole (Frey, 2015; Kritz \& Gurak, 2015; Lichter \& Johnson, 2009; Suro \& Singer, 2003). Key forces promoting Hispanic

\footnotetext{
3. As a matter of convenience, we include Puerto Rico when discussing Hispanic countries of origin despite its status as a U.S. territory.
} 
dispersion include the "push" of ethnic market saturation in traditional gateways and the twin "pulls" of housing affordability and economic restructuring in secondary community destinations, which offer low-skill jobs in the manufacturing, construction, and service sectors (Jones, 2008; Light, 2006; Massey, 2008; Waters \& Jimenez, 2005). Such destinations have also become viable options as a result of changes to U.S. immigration policy (Durand et al., 2006; Tienda \& Sanchez, 2013). In particular, the 1986 Immigration Reform and Control Act legalized some 3 million newcomers, mainly from Mexico, and made it easier for them to move about the country. Border hardening strategies, state legislation, and local ordinances have also deflected Mexican migrant flows in new directions (Light, 2006; Massey \& Capoferro, 2008; Varsanyi, 2010; Walker \& Leitner, 2011).

For many Latinos, upward socioeconomic mobility facilitates consideration of a wider range of destinations. In line with assimilation theory, the appeal of gateway metropolises may gradually diminish in response to the gains in education, earnings, citizenship, English proficiency, and other indicators of advancement that most Hispanic origin groups experience in American society (Alba \& Nee, 2003; Clark, 2003; Kasinitz et al., 2008; Tran \& Valdez, 2017; Waters \& Jiminez, 2005; White \& Glick, 2009). As incorporation proceeds across generations, group members are better able to seek economic and quality-of-life opportunities in new metro destinations as well as established ones (Funkhouser, 2000; Singer et al., 2008). Some recent immigrants have even settled directly in new destinations upon their arrival in the United States after learning about them via family, co-ethnic, or employment networks (Lichter \& Johnson, 2009; Singer et al., 2008).

Regardless of where one's last residence was located (inside or outside the U.S.), some research shows the positive selection of immigrants (e.g., on education and documentation status) who move to secondary destinations and the potential benefits from them doing so, as indexed by higher employment and earnings and exposure to less segregated residential contexts (Hall, 2009; Lichter \& Johnson, 2009; McConnell, 2008; Park \& Iceland, 2011). The literature, however, remains far from unanimous. For instance, several studies have reported mixed or negative results on residential, school, labor force, acculturation, and discrimination measures for Latinos living in destinations beyond the primary gateways (Dondero \& Muller, 2012; Fischer \& Tienda, 2006; Hall, 2013; Lichter et al., 2010; Oropesa \& Jensen, 2010; Tran \& Valdez, 2017).

Such results do not change what the forces of dispersion portend in response to our initial research question. Regardless of origin group, Latinos are anticipated to have spread across a larger number of metropolitan areas between 1990 and 2010, yielding a more even locational distribution nationally. The second question concerns exactly where Hispanic origin groups are dispersing to. Based on factors identified in the preceding paragraphs, a reasonable scenario would seem to be growing spatial convergence among groups over time. As members of all groups pursue opportunities farther afield (i.e., not only in major gateways), overlap in their metro areas of residence should increase (see Durand et al., 2006, p. 87-88). Stated more precisely, metro-level locational differences between any pair of origin groups may diminish during the 20 -year period of interest as both groups find many of the same secondary destinations attractive. However, distinctive settlement histories and 
demographic profiles could also foster geographic preferences that serve to keep certain groups apart. This alternative scenario—which emphasizes persistent separation—receives more attention in the following sections.

\section{Enduring concentration}

Given the popularity of research on newer Hispanic destinations, making a case for the traditional gateway destinations may seem dated. Yet the forces that promote dispersion from these gateways often operate in a complex push-and-pull manner with the forces sustaining them (Lichter \& Johnson, 2009). At the same time that many Latinos are drawn to emerging destinations, many others continue to reside in a handful of primary metro gateways, a degree of geographic concentration epitomized by the Cuban enclave in Miami (Alberts, 2006). From a historical settlement perspective, certain areas initially appeal to an ethnic immigrant group because of their high labor demand and their physical proximity to the group's country of origin (Lieberson \& Waters, 1988; Portes \& Rumbaut, 2006). Over time, group-based resources - in the form of social networks, institutions, and employment - accumulate in these gateway areas, fostering the development of self-sustaining ethnic communities that not only provide benefits but shield individuals from the hostile reception they might experience in places unaccustomed to diversity.

Reputation as an ethnic "comfort zone," coupled with local economic opportunity, enhances the ability of a gateway metropolis to attract and retain members of specific groups (Bartel \& Koch, 1991; Ellis \& Goodwin-White, 2006; Foner, 2013; Frey \& Liaw, 1999; Kritz et al., 2011). This does not mean that everyone stays put; some Latinos will inevitably move elsewhere. Instead, the relevant dynamic is path dependence, with historical sites of group concentration building momentum toward the future. For the purposes of our first research question, path dependence suggests that most members of a given Hispanic origin group will have remained heavily concentrated in one or a few traditional gateway areas between 1990 and 2010.

Alternatively, it could imply relative stability in the group's distribution throughout the metropolitan hierarchy. That is, where metro areas rank vis-à-vis each other in the shares of all group members that they capture may change little even though the shares themselves change in size. Over time, for example, the area with the second largest percentage of a particular origin group's members nationally might gain ground on the principal gateway for that group but still fall short of it. Gaps could narrow or widen among other pairs of metro areas in their shares of the group in question yet leave their ordinal positions intact. In empirical terms, this would show up as a high correlation between time points in metro rank ordering on group share.

Path dependence also speaks to our second research question, about the likelihood of different Latino origin groups converging on the same metro areas during the urban diaspora of the 1990-2010 period. In essence, the enduring concentration of an origin group in a few large gateways reflects the importance of a group's starting point when it enters the U.S., including where its members first settle (Lieberson \& Waters, 1988; Portes \& Rumbaut, 2006). To the extent that initial destinations are group-specific, we would anticipate little convergence in the subsequent redistribution of distinct groups across the metro system. 
Admittedly, the evidence on Hispanic dispersion to secondary destinations (cited previously) appears to reduce the odds that origin groups would remain heavily concentrated in a small number of gateway metropolises over multiple decades. However, such a pattern should not be dismissed prematurely. For one thing, sites for new destination case studies are often chosen because of an explosive Latino growth rate that is due in part to the miniscule size of the group's initial population. As migration data suggest, any dispersion of Hispanics toward nontraditional locations in recent decades is likely to have been swamped by the sheer volume of Hispanic immigrants headed to major gateway areas (Frey \& Liaw, 1999; Lichter $\&$ Johnson, 2009). Also, the treatment of Hispanics in panethnic fashion-as a single, undifferentiated aggregate-may obscure persistent gateway concentration among particular origin groups.

\section{Exposure to diversity}

A recurrent theme in research on Latino settlement trends concerns the consequences of concentration versus dispersion, with a mix of costs and benefits thought to accompany each pattern. Our interest lies in what these patterns imply for origin group members' exposure to ethnoracial diversity. Intuitively, types of employment, access to institutional resources, political clout, and other outcomes for Latinos may be influenced by the sizes of the panethnic populations with which they share a metropolitan area. Some evidence suggests that higher diversity - more equal panethnic proportions—serves as a buffer, reducing racial segregation (DeFina \& Hannon, 2009; Parisi et al., 2015). At the same time, a rise in diversity could fuel distrust, conflict, and "hunkering down" (Laurence, 2014; Putnam, 2007; van der Meer \& Tolsma, 2014). These effects hint that both the magnitude of diversity and the relative numbers of Whites, Blacks, Hispanics, and Asians encountered by Hispanic metro dwellers are worth investigating. Thus, our third research question asks in part if exposure to panethnic diversity by Latino origin groups has changed since 1990 .

A corollary to this question has to do with changes in Latinos' exposure to members of their own country-of-origin group compared with their exposure to other such groups. Rather than posit a common bond among all origin groups inhabiting the same metropolitan area, one could argue that many outcomes attributed to diversity are also shaped by the relative size of an origin group, its members' affinity toward each other, and their aversion to other groups (Lee et al., 2017). A Mexican-origin political candidate, for example, would likely fare better in a community with a large Hispanic population dominated by Mexicans rather than Dominicans. Limits to Latino panethnic cohesion - and to any supposed benefits associated with that cohesion-should be expected, given the degree to which the component groups vary in characteristics like U.S. citizenship, English proficiency, socioeconomic status, racial composition, and family structure (Durand et al., 2006; Landale et al., 2006; Logan \& Turner, 2013; Rumbaut, 2006; Saenz \& Morales, 2015). To capture ethnoracial exposure in the more nuanced way proposed here, we estimate the diversity experienced by the average member of a focal Latino origin group based on how evenly metro populations are divided among large panethnic categories (e.g., Whites, Blacks, Asians), the focal group of interest, and a residual category comprising all other Hispanics. 


\section{Origin group differences}

Underlying any analysis of Hispanic country-of-origin groups is an assumption about the varied nature of their experiences. Several factors may lead to differences in the spatial redistribution of these groups across metropolitan areas. For example, segmented assimilation theory (Portes \& Zhou, 1993) suggests that position in the American racial hierarchy could play a role, slowing the dispersion of darker-skinned groups with African ancestry - such as Dominicans and Puerto Ricans-away from major metro gateways. Alternatively, we might expect dispersion to be greater for origin groups who fare well in levels of education, income, citizenship, English proficiency, and other indicators of societal incorporation. Cubans and Colombians rank highly on these indicators, in contrast to Guatemalans (Logan \& Turner, 2013; Lopez, 2015). Duration of residence in the U.S., a correlate of incorporation, might also boost dispersion. This effect should be pronounced for Mexicans, the group with the longest history in the host country by virtue of its roots in a neighboring nation that once contained a large portion of California, the American Southwest, and the Rocky Mountain West within its borders (Foley, 2014).

Mexicans are hardly the only group whose metropolitan settlement pattern has been shaped by geographic, historical, and political circumstances. Due to its proximity to the sending nation, Miami persists as the main metro gateway for Cubans, whose power has long been consolidated there (Alberts, 2006). Salvadorans and Guatemalans, however, are presumably less likely to exhibit a high degree of gateway concentration in light of their recent arrival in the U.S., after the economic and policy changes promoting dispersion had already begun to operate (Hamilton \& Chinchilla, 2001). Puerto Ricans represent an ambiguous case. One the one hand, cheap airfares between San Juan and New York City in the 1950s spatially focused the mass migration of Puerto Ricans, establishing New York as their principal gateway (Rumbaut, 2006). On the other hand, their legal status as American citizens confers upon them a freedom of movement that seems more conducive to dispersion than concentration.

Finally, we should expect origin group differences in Latinos' exposure to racial and ethnic diversity. As a rule, gateway metropolises are quite diverse while nontraditional destinations tend to be more homogeneous, i.e., Whiter (Lee et al., 2014). This suggests that groups with higher levels of gateway concentration, such as Dominicans, should experience greater diversity than Mexicans or other groups that have spread throughout the metropolitan system. The more general point here is that answers to all three of our research questionsabout the extent and locational convergence of metro Hispanics' redistribution as well as their exposure to ethnoracial diversity - will depend upon the relative strength of the forces promoting dispersion and concentration for each origin group.

\section{Methodology}

\section{Census data}

We address the three questions with data from the summary files (SFs) of the 1990, 2000, and 2010 decennial censuses. For each year the race by Hispanic origin cross-tabulation in SF1 yields counts of Hispanics of any race and of non-Hispanic Whites, Blacks, Asians, 
Pacific Islanders (first tabulated separately from Asians in 2000), Native Americans (American Indians and Alaska Natives), multi-race individuals (first recognized in 2000), and those reporting some other race. We combine Asians and Pacific Islanders, hereafter labeled Asians, throughout the 1990-2010 period. An "other" category has also been created that consists of Native Americans and multi-race and other-race individuals. ${ }^{4}$ These recoding efforts result in five panethnic populations-Hispanics and non-Hispanic Whites, Blacks, Asians, and "others"- that are exhaustive, mutually exclusive, and largely comparable over time. Each population includes members born in the U.S. and abroad.

The SF1 data are further exploited to distinguish among Hispanics from different backgrounds. Items in the census questionnaire permit Latino respondents to report more specific identities based on country of origin or ancestry. The seven origin groups featured in our study, ranked by size, are Mexicans, Puerto Ricans, Cubans, Dominicans, Salvadorans, Guatemalans, and Colombians. They represent the largest groups within their panethnic population, accounting for $86 \%$ of all native- and foreign-born Hispanics nationally in 2010 (Ennis et al., 2011). One reason that we focus on the last two decades is the absence of data on the more recently arrived groups (Dominicans, Salvadorans, Guatemalans, and Colombians) prior to 1990. While results are presented for all three census years, data quality issues with the reporting of country of origin in 2000 have led us to emphasize the beginning and ending time points. ${ }^{5}$

Both the Hispanic panethnic population and the origin groups comprising it must be situated in metropolitan areas to address our research aims. Metro areas approximate functional domains (i.e., housing and labor markets) where people live and work. As operationalized by the Census Bureau, they contain at least one urbanized population of 50,000 or more, the central county (or counties) in which that population is located, and any surrounding counties that share strong commuting ties with the central county (Frey et al., 2006). We impose December 2009 Office of Management and Budget geographic definitions to obtain a sample of 363 metro areas with constant boundaries from 1990 through 2010. These areas are home to more than four-fifths of all Americans (Wilson et al., 2012).

\section{Entropy index}

The entropy index, a measure of diversity symbolized by $E$, rests on the concept of evenness: how equally members of a population are spread over a set of categories (for more details, see White, 1986). In the case of spatial distribution, the more equal the shares of Latino residents across a greater number of metropolitan areas, the higher their level of locational diversity—or, in our terms, their dispersion—will be at a given point in time. Formally,

\footnotetext{
4. Collectively, the members of the "other" category constitute less than $3 \%$ of the U.S. total in all three census years.

5. Several investigators have criticized the quality of 2000 census data on Hispanic origin, citing a large, unexpected rise over 1990 figures in the percentage of Latino respondents identifying as "other Hispanic" and a corresponding dip in the percentages identifying with smaller origin groups (Logan, 2001; Martin, 2002; Suro, 2002). These shifts appear attributable to a series of changes in census questionnaire design between 1990 and 2000, most notably the removal of example origin groups for respondents to write in if they fell outside the Mexican, Puerto Rican or Cuban check-box categories. Fortunately, the 1990 version of the Hispanic origin module was reinstated in 2010. To minimize concerns about lack of comparability, we stress 1990 and 2010 results throughout the analysis.
} 


$$
E=\sum_{r=1}^{R} p_{r} \ln \left(\frac{1}{p_{r}}\right)
$$

where $p_{r}$ refers to metro area $r^{\prime}$ s proportion of all persons belonging to a particular origin group and $R$ signifies the number of areas. When $p_{r}$ equals 0 , the contribution of that area to the spatial dispersion of the group is defined as 0 . Because the entropy index does not have a fixed upper limit, we have created a standardized version, dividing each $E$ score by its maximum (the natural $\log$ of $R$, or 5.894 for 363 metro areas) then multiplying by 100 . A value of 100 is interpreted as complete dispersion, with every metro area occupied by the same share (1/363 $\left.{ }^{\text {rd }}\right)$ of all focal group members. An $E$ of 0 reflects complete concentration, when all group members reside in a single area. For our first research question, an unweighted version of $E$ is employed.

Although $E$ provides an economical measure of dispersion to answer that question, it does not tell us in which metro areas Hispanics are more (or less) concentrated. To make visible this aspect of dispersion, we examine the distribution of each origin group population across three classes of metro areas: the ten areas with the largest numbers of group members (referred to as primary gateways), the 40 with the next largest numbers (secondary destinations), and the remaining 313 (other destinations). As areas climb up or fall down the group population rankings from one census year to the next, they may shift to a different class. The particular area in which a group is most heavily concentrated-what we call its principal gateway—receives attention as well. An important feature of our classification scheme is that, unlike most destination typologies, it defines group-specific sets of metro areas that have constant Ns over time and thus permits the tracking of each group's redistribution among areas with larger and smaller shares of that group. ${ }^{6}$

Later in the analysis (for the third research question) we employ the entropy index in another way: as a measure of the ethnoracial diversity of metropolitan areas, or how evenly distributed an area's total population is among White, Black, Asian, and "other" panethnic categories, a focal Hispanic origin group, and all other Hispanics. Recognizing each origin group separately from the remainder of the area's Hispanic population yields a different, more refined $E$ score than if all origin groups were combined in panethnic fashion. As before, standardization entails dividing $E$ by the natural $\log$ of the number of categories (1.792 for six categories) and multiplying by 100. If each ethnoracial category makes up one-sixth of a metro area population, the $E$ value for the area would be 100 , indicating maximum diversity. But when all metro residents belong to the same group, the metro population is fully homogeneous, resulting in an $E$ of 0 (no diversity).

\footnotetext{
6. Alternative destination typologies are available, but none that we are aware of is ideal for present purposes. Most classify metro areas or other geographic units based on the representation and growth of their total foreign-born (immigrant) populations (Lee et al., 2014; Singer, 2005) or their Hispanic panethnic populations (Lichter and Johnson, 2009; Lichter et al., 2010; Suro and Singer, 2003). Hall's (2013) analysis of residential segregation among immigrant origin groups in established, new, and minor destinations stands as a partial exception, recognizing that an area's destination status may differ from one group to the next. However, only three of our Hispanic origin groups are among the 10 groups covered by his study, which includes immigrants from Asia and the Caribbean as well as Latin America.
} 
To transform $E$ so that it reflects Latino exposure to diversity, we multiply it by the ratio of a focal origin group's population in each metro area within a particular class of areas (e.g., 2010 primary gateways) to the group's total population across all areas in that class. The adjusted $E$ s for the individual areas are then summed to produce a weighted group-specific entropy index for the class as a whole. This procedure ensures that if the share of the focal group in one metro area is double that in another area, the contribution of the former area to the overall $E$ index for the class will be twice as large. Thus, the weighted indices convey the level of ethnoracial diversity experienced by the average Mexican, Dominican, or other group member living in a given type of metro area in a specific census year.

As in the case of spatial dispersion, the weighted entropy index is a valuable tool but it conceals information, namely about the particular ethnoracial populations to which Latinos are most and least exposed. We capture this dimension of diversity with compositional bar graphs that reflect the relative sizes (percentages) of the six racial-ethnic categories.

Weighted by the same ratio applied to metro $E$ values, the modified percentages depict the local racial-ethnic composition to which the average focal group resident of a given class of metropolises is exposed. We are especially interested in how exposure to Whites and Blacks, to one's own origin group, and to other Hispanics has changed. The estimation of own-group exposure is made possible by unpacking the Hispanic panethnic population one focal group at a time.

\section{Dissimilarity index}

Unlike our first and third research questions, the second question addressed below-about geographic convergence among Latino origin groups over time-requires a measure other than $E$, one that compares the distribution of groups throughout the metropolitan system. For this purpose, we compute an unweighted version of the well-known index of dissimilarity, or $D$ (Massey \& Denton, 1988; White, 1986) for pairs of origin groups in 1990, 2000, and 2010, determining how distinct the proportional distributions of two groups are from each other across all 363 metropolitan areas. ${ }^{7}$ Because the computation of $D$ relies on group proportions, it is insensitive to differences in group size. Hence, the distribution of Mexicans (the largest origin group) across areas can be compared to that of Colombians (the smallest group). The way that we have calculated it, $D$ can range from 0 to 1 : the former value reflects an even distribution of the two groups across metro areas while the latter indicates maximum dissimilarity in their distributions (i.e., no sharing of areas). Moreover, $D$ has an intuitively appealing interpretation, telling us what proportion of the members of one group would need to move to different metro areas to achieve distributional equality with the members of another group. The lower that proportion becomes, the more overlap there is in the areas where the two groups reside, consistent with a pattern of convergence.

\footnotetext{
7. Although the index of dissimilarity is often employed to study residential segregation across neighborhoods, its general functioncomparing the evenness (or lack thereof) in the proportional distributions of groups across categories-has relevance for other topics and geographic scales. For example, research on male-female differences in types of occupations has long utilized some version of $D$ (e.g., Jacobs, 1989). And, similar to our analysis, Saenz and Morales (2015:63-64) have compared the geographic distribution of Latino origin groups to that of the U.S. population as whole, but across states rather than metropolitan areas.
} 


\section{Results}

\section{Are origin groups dispersing?}

The first question guiding our analysis asks to what degree the seven Hispanic origin groups have dispersed across metropolitan areas during the new diaspora. Each cluster of three vertical bars in Figure 1 shows how a group's dispersion (measured with the entropy index) changes from 1990 to the present. The consistent upward stair-step pattern in standardized $E$ scores indicates that every group has become spread more evenly throughout metropolitan America. Increases in dispersion are largest for Guatemalans and Salvadorans (between 1990 and 2000) and Dominicans (between 2000 and 2010) among the newer immigrant groups. Puerto Ricans constitute the sole established group to experience substantial dispersion. Mexicans and Cubans exhibit minimal gains in dispersion, similar to the Latino population as a whole. (The overall Latino $E$ has risen about seven points, from 63.4 in 1990 to 70.8 in 2010.) High levels of Mexican dispersion from 1990 onward operate as a 'ceiling', explaining the small gains made by this group.

The potential for dispersion can be inferred from the extent of group concentration in one or a few metropolitan areas. Figure 2 displays the percentage of metro origin group members nationally residing in the principal gateway for each group from 1990 through 2010. Only three metropolises serve as principal gateways: (1) New York for Puerto Ricans, Dominicans, and Colombians, (2) Los Angeles for Mexicans, Salvadorans, and Guatemalans, and (3) Miami for Cubans. Each group's principal gateway has remained the same at all three time points, suggesting a degree of path dependence. That gateway is also among the leading growth centers for six of the groups, with 1990-2010 absolute gains ranging from 75,473 (for Colombians in New York) to 1.4 million (for Mexicans in Los Angeles). Puerto Ricans are the lone group to decline in their principal gateway over time. New York's Puerto Rican population of 1.2 million in 2010 has 7,283 fewer members than it did two decades earlier.

The shorter 2010 than 1990 bars in the figure demonstrate that all principal gateways have become less popular in relative terms. Yet the details of this trend vary markedly across origin groups. Dominicans, for example, stand out because of their high degree of concentration in New York. Nearly four-fifths of all metropolitan Dominicans inhabited New York in 1990; three-fifths still do by 2010. Cubans are also strongly concentrated, threefifths living in Miami. Unlike Dominicans, however, their principal gateway proportion has changed little over time, hinting at limited potential for a future decrease in Miami's dominance. At the other extreme, a much smaller share of all Mexicans resides in Los Angeles. The Mexican population of Los Angeles continues to grow but less rapidly than elsewhere. The result is a decline in the percentage of metropolitan Mexicans in LA, from $25 \%$ to $15 \%$ since 1990 .

Puerto Ricans, Salvadorans, Guatemalans, and Colombians exhibit similar magnitudes of and declines in concentration. Between $40 \%$ and $50 \%$ of each group's membership occupied its principal gateway at the beginning of the study period, but that share falls to about onefourth by the end. Deconcentration is most pronounced for Guatemalans, with Salvadorans a close second. Both of these groups are recent arrivals to the U.S. (Hamilton \& Chinchilla, 
2001). They have also undergone a robust expansion in Los Angeles that fails to match their pace of growth in other metro areas. Their trajectory thus parallels that of Mexicans, albeit at higher levels of principal gateway concentration for the moment. The resemblance to Mexicans may well increase with longer duration of Guatemalan and Salvadoran residence in America.

Table 1 demonstrates that the dispersion of Hispanic origin groups extends beyond their primary gateways. Aside from Mexicans, roughly three-fourths or more of each group's population lived in its 10 primary metro areas in 1990 but that share typically shrinks between 8 and 15 percentage points by 2010. Guatemalans have experienced the greatest decline in top 10 residence, from $86 \%$ to $64 \%$. At the same time, $36 \%$ of that group can now be found in nontraditional metro settings ( 40 secondary destinations +313 other destinations), up from 14\% two decades earlier. The shares in such settings have more than doubled for Salvadorans (from 9\% to 24\%) and Dominicans (from 6\% to 15\%), and significant relative increases are apparent for Puerto Ricans, Cubans, and Colombians as well. These redistributional patterns reflect the collective influence of the forces promoting dispersion, net of the retentive factors associated with gateway concentration. ${ }^{8}$

In a separate analysis (not shown; available from the authors upon request), we identify the 15 major growth centers for each group in each region of the country. ${ }^{9}$ Average 1990-2010 growth rates in such centers are impressive for all groups in all regions and especially striking for metropolitan Guatemalans, Salvadorans, and Dominicans. The growth recorded by these three groups is understandable given their typically small initial populations, which amount to a 'floor' from which the most likely direction of change is upward. By way of illustration, since 1990 Denver has witnessed a 22-fold increase in its Salvadoran population (from 355 to 7,784), Reading, PA a 34-fold increase in Dominican residents (from 310 to 10,545), and Richmond a 110-fold increase in Guatemalans (from 48 to 5,303).

Geographically, the pace of growth of the Latino origin groups tends to be greatest among smaller metro areas throughout eastern Pennsylvania (e.g., Allentown, Reading, Scranton); in midwestern metropolises such as Indianapolis, Cincinnati, and Sioux City; in the New South locations of Charlotte, Raleigh, Atlanta, and Nashville; in metropolitan Florida other than Miami (Cape Coral, Naples, North Point, Orlando); and in western areas outside of California (Phoenix, Las Vegas, Portland, Seattle, Denver). Not surprisingly, many of these areas have become emerging gateways or new destinations for the Hispanic population in general (Frey, 2015).

The proliferation of nontraditional destinations has altered the standing of the metropolises in which the more recently-arrived origin groups reside. To demonstrate this, we calculate Spearman correlations between the 1990 and 2010 rank distributions of the metro areas occupied by each group. The lower coefficients for Guatemalans (Spearman $r=.70$ ),

\footnotetext{
8. Despite our metropolitan focus, members of the seven Latino origin groups also live in nonmetropolitan settings. As of 2010, the shares of all Mexicans (8.9\%), Guatemalans (6.4\%), Puerto Ricans (4.5\%), Cubans (2.9\%), Salvadorans (2.7\%), Colombians (2.3\%), and Dominicans (1.3\%) found in nonmetro America remain modest. This assessment holds both in an absolute sense and relative to their representation in each class of metro destination shown in Table 1. Nonmetro shares were lower two decades earlier for six of the seven groups, with only Mexicans (8.9\% in 1990) failing to record an increase.

9. Metro areas qualify as growth centers if they rank among the 15 areas in a census-defined region that experience the largest absolute increases in population for the origin group of interest.
} 
Salvadorans (.75), and Dominicans (.79) reveal non-trivial shifts in their metropolitan hierarchies, consistent with the spread of the groups across a wider range of locations. However, greater stability characterizes the hierarchies of the established groups, as suggested by $1990 \times 2010$ rank-order correlations at or close to .90 for Mexicans, Puerto Ricans, and Cubans. These results can be understood, once again, in terms of both dispersion and concentration dynamics, with the relative strength of the two contingent upon the group in question.

\section{Convergence vs. separation}

The second research question we address is whether the dispersion of Hispanic origin groups has converged geographically or whether the groups can be found in different destinations. That is, are groups now sharing the same metropolises or living in separate ones? The overlap in principal gateways and regional growth centers suggests that some groups might be converging. To further evaluate this possibility, we compute the unweighted index of dissimilarity $(D)$ for all pairs of origin groups across the 363 metropolitan areas in each census year. As a reminder, a higher $D$ indicates greater separation between the metro areas occupied by two groups; lower $D$ s indicate more convergence in the groups' locations.

The $D$ values from this exercise, shown in Table 2, convey three main messages. First, they typically drop a few points during each decade. This is confirmed by the 1990, 2000, and 2010 mean $D$ scores $(.62, .59$, and .57 respectively) calculated from the $D$ s for the 21 distinct pairs of groups in each panel of the table and by the fact that each group exhibits a small but steady decrease in its own average $D$ with the other six groups throughout the study period (far right column). While a few pair-specific $D$ scores increase or stay the same in successive census years—see, for example, the 1990 and 2000 Puerto Rican-Dominican $D$ s or the 2000 and 2010 Colombian-Dominican $D$ s-they constitute exceptions to the modest downward trend.

Second, many of the 2010 scores are substantial in magnitude, with 11 of the 21 exceeding .60, a common threshold for high dissimilarity. As an illustration, the DominicanMexican $D(.88)$ means that nearly nine-tenths of all Dominicans (or Mexicans) would have to relocate to different metro areas to be spread throughout metropolitan America in a manner identical to the other group. The geographic separation of Dominicans and Mexicans is apparent in the map shown in Figure 3. Each light blue-colored metro area contains one of the 50 largest Dominican populations as of 2010 (10 primary gateways +40 secondary destination); each orange-colored area contains one of the 50 largest Mexican populations. While the former are found mainly in states along the eastern seaboard (Anchorage being a notable outlier), the latter tend to be located in California, the Pacific Northwest, Texas, and other parts of the western U.S. Only 14 'shared' metropolises (colored light yellow) fall in the top 50 for both groups, and even this degree of convergence is misleading. Because of Dominicans' heavy concentration in New York-the sole shared area where they outnumber Mexicans-42 of the remaining 49 largest Dominican metro populations each represent less than $1 \%$ of the group's national total. Mexicans, on the other hand, are distributed more evenly. Yet their presence in their principal gateway of Los Angeles, another shared area, is still 1,000 times greater than that of Dominicans (2010 populations of 4,368,745 and 4,358). 
The third message from Table 2 is about how levels of locational dissimilarity vary across pairs of groups. As of 2010, Salvadorans are regularly found in the same areas as Guatemalans $(D=.24)$ and Colombians in the same areas as Puerto Ricans $(D=.31)$. Indeed, Guatemalans and Colombians exhibit mean $D$ s well below those for Mexicans, Cubans, and Dominicans. Given this variation, we are unable to draw a straightforward conclusion. Rather, the convergent settlement pattern associated with dispersion applies to a couple of pairs of Hispanic origin groups at the same time as some pairs have continued to live in largely separate metropolitan areas. Others fall in between, exhibiting moderately dissimilar (or similar) distributions across areas.

\section{Diversity exposure across metro contexts}

The final question motivating our research asks how the exposure of Latino origin groups to diversity has changed during the new urban diaspora. We again use the entropy index, this time to measure the magnitude of ethnoracial diversity - the equality in size of the White, Black, Asian, non-Hispanic "other," focal Hispanic origin, and other Hispanic populations within metropolitan areas-from 1990 through 2010. Recall that the $E$ scores have been weighted to capture the diversity experienced by the average member of a focal Hispanic origin group who resides in a particular type of metro setting.

These $E$ scores are displayed at the right edge of the compositional bars in Figure 3. They show that, for a given year, differences in racial-ethnic diversity magnitude among groups are small regardless of metro context. Another consistent pattern emerges when comparing 1990 Es (upper bar), 2000 Es (middle bar), and 2010 Es (lower bar): all groups have experienced steadily increasing exposure to diversity in all types of metro areas over the two decades. At each time point diversity levels are highest for the 10 primary gateways, intermediate for the 40 secondary destinations, and lowest for the 313 other destinations. The 313 areas in the last class undergo the greatest percentage increases in exposure to ethnoracial diversity. Nevertheless, their $2010 E$ scores and those for the secondary areas fall short of the 1990 Es for the top 10 Cuban, Dominican, Guatemalan, and Salvadoran metro gateways and they fall short of the 2000 Es for the top 10 Mexican, Puerto Rican, and Colombian gateways, suggesting a lag of 10 to 20 years or more in the magnitude of diversity exposure.

The compositional bars in the figure depict the racial-ethnic structure of diversity, i.e., the weighted mean proportional representation of the six ethnoracial populations underlying each $E$ score. According to the uppermost panel, the average Mexican resident of the 10 primary Mexican gateways in 1990 lived in an area with a slim White majority; by 2010 White representation had dropped to roughly two-fifths, matched in size by the combination of Mexican (focal group) and other Hispanic shares. An approximation to this pattern holds for the 40 secondary Mexican destinations but not for the 313 other destinations, which retain a solid albeit diminished White majority at the end of the study period. In each type of metro area, the mean proportion of non-Mexican Latinos (the six other origin groups + other Hispanics) has barely increased over time. Black, Asian, and "other" proportions to which the average Mexican was exposed show similarly modest changes from 1990 through 2010. 
One finding of note is that Mexicans' exposure to Blacks is the lowest of any Latino origin group. Throughout the study period, the average Mexican lived in a metropolitan context where African Americans constituted no more than one-tenth of the population, a generalization applicable to primary gateways and secondary and other destinations. This differential distribution of Mexicans and Blacks across metro areas has likely contributed to the complexity of Black-Latino relations, which reflect an awareness of common interests but also perceived threats posed by the opposite group in social, economic, and political domains (Teslles et al., 2011). Mexicans are distinctive in another way: their exposure to their own group in the 40 secondary destinations as well as the 10 primary Mexican gateways far exceeds the own-group exposure of all other focal origin groups. The simple reason for this is that Mexicans tend to inhabit metro areas with many Mexicans, who dwarf every other origin group in size (Lee et al., 2017).

Compared to the Mexican case, Dominicans' and Puerto Ricans' exposure is marked by a higher Black proportion, consistent with their location in the eastern half of the country (including the Northeast and portions of the Midwest and South) where many African Americans reside. The average members of these two origin groups have also lived among a White majority at all three time points in all three types of metropolitan settings. Cubans and Colombians residing in their 10 primary gateway areas have been exposed to sizeable Latino proportions in each year and to a White minority by 2010; neither of these conditions occurs outside of the top 10. Aside from Mexicans, Cubans are the only group to experience a nontrivial own-group presence, and only in Miami and other primary gateways where an average of $13 \%$ of their fellow residents are also Cuban as of 2010. Finally, diversity exposure for Salvadorans and Guatemalans resembles that for Cubans and Colombians, although Salvadorans and Guatemalans live among more Hispanics in their respective secondary and other metro destinations.

\section{Conclusion}

This study contributes to the literature on Latino spatial redistribution in the United States. Paralleling the current interest in new rural destinations, it updates what is known about the diaspora across metropolitan areas, where over nine-tenths of all Hispanics (native and foreign born) live. A key contribution of our work involves the unpacking of the Hispanic panethnic population, which reveals differences among specific country-of-origin groups in their changing locational patterns from 1990 through 2010. The foundation for the analysis is laid via discussion of some of the factors that drive, often in simultaneous or complementary fashion, group tendencies to concentrate and disperse at the metropolitan scale.

In response to the initial research question, we find that all seven Latino origin groups have become spread more equally throughout metropolitan America. Their trajectories, however, diverge in detail. Mexicans and Cubans exhibit small increases in dispersion, but the former group was already highly dispersed in 1990 while three fifths of the latter's members remain concentrated in the Miami metro area two decades later. Puerto Ricans are the only established origin group to have undergone a non-trivial degree of dispersion. More marked dispersion is apparent for the four newer groups, with Guatemalans leading the way, 
although three-fifths of all metropolitan Dominicans still call New York home. One implication of path dependence - that the rankings of each group's gateway, secondary, and other metro areas should stay the same over time-receives less support for the newer groups than the older ones.

Results pertaining to the second research question are also mixed. Dissimilarity in how Latinos are distributed across metropolitan areas has declined by modest amounts for most pairs of origin groups, in line with the convergent settlement scenario. At the same time, some pairs of groups (e.g., Dominicans and Mexicans) continue to occupy separate sets of metropolitan areas. With respect to our third question, exposure to ethnoracial diversity increases throughout the 1990-2010 period in all types of metro settings, yet the magnitude of diversity exposure is far higher among Latinos who reside in one of their group's 10 primary gateways than elsewhere. Mexicans are exposed to larger percentages of Hispanics and own-group members but smaller percentages of Blacks than any other origin group, a finding that holds across types of metro contexts. Three pairs of groups (Dominicans/Puerto Ricans, Cubans/Colombians, and Salvadorans/Guatemalans) display exposure patterns that differ from each other as well as the Mexican pattern.

What these findings underscore is the remarkable variation among Latino origin groups in their post-1990 metropolitan redistribution trends. Such variation suggests that multiple diasporas are underway rather than a single, uniform one, ultimately shaping origin-group diversity within metro Hispanic populations. Because distinct origin groups continue to be spread unevenly across metro areas, local Hispanic communities should differ in the number and sizes of the origin groups constituting them. For example, a recent study shows that many communities consist of one dominant group (Mexicans) while others are more equally divided among a few groups (Lee et al., 2017). The magnitude and structure of Latino diversity in a metro area may have implications for everything from group members' ethnoracial self-identification (in panethnic or origin-group terms) to service needs and the ability of groups to engage in collective political action. Examining the potential consequences of Latino diversity at the local level strikes us as a useful next step in this line of research.

Along similar lines, we would like to see a more nuanced analysis of how divergent Hispanic redistribution patterns influence the character of ethnoracial relations among Latino, Black, and White metropolitan dwellers. Past research on such relations has often treated them as a function of the extent of between-group contact, perceived economic and political competition, and prejudice and racial distancing (Telles et al., 2011). Groups' regard for each other also appears to be context-specific, reflecting features of the community under investigation (Massey, 2008). One question raised by our results is whether differences across metro areas in incumbent residents' reactions to Latinos depend in part upon the newcomers' origins. That is, do certain Latino origin groups elicit more positive responses from Whites than others do? Which origin groups are African Americans more (or less) favorably inclined toward, if any? Or do Whites and Blacks both tend to lump all Hispanics together, viewing them in an undifferentiated panethnic manner? 
Finally, Latino origin-group redistribution should be explored into the 2020s and beyond. The combination of a youthful age structure and relatively high fertility ensures that Hispanic population growth will enjoy considerable momentum. But this growth need not translate automatically into greater dispersion. Keep in mind that the period spanned by our study largely predates the spate of federal, state, and local efforts to do something about unauthorized immigration, often in ways that have altered the perceived attractiveness of particular destinations, not to mention the nation as a whole (Varsanyi, 2010; Walker \& Leitner, 2011). If once-favorable metropolitan contexts of reception are viewed by Latinos as less welcoming, the pace and direction of dispersion may change for some groups. Evidence on interstate migration is consistent with this expectation, showing that all Latinosincluding U.S. natives as well as noncitizens and the naturalized foreign born-became less likely after 2007 to move to states with 'hostile' policies toward undocumented immigrants (Ellis et al., 2016; but see Parrado, 2012). Dispersion across counties has also slowed after the Great Recession, and more people now migrate from the U.S. to Mexico than vice-versa (Stepler \& Lopez, 2016). Whether these trends persist, how they manifest at the metro scale, and what they mean for the settlement patterns of specific Latino origin groups are key issues to be addressed in future investigations.

\section{Acknowledgments}

A version of this article was presented at the 2018 meeting of the American Sociological Association in Philadelphia. We thank Chad Farrell, John Iceland, and Megan Evans for helpful comments on earlier drafts.

Funding

Support for this research has been provided by a grant from the Eunice Kennedy Shriver National Institute of Child Health and Human Development (R01HD074605). Additional support comes from the Population Research Institute at Penn State, which receives infrastructure funding from NICHD (P2CHD041025). The content of the article is solely the responsibility of the authors and does not reflect the official views of the National Institutes of Health.

\section{Biography}

Barrett A. Lee is Professor of Sociology and Demography at The Pennsylvania State University. His research focuses on spatial manifestations of social organization and inequality, spanning such topics as community racial-ethnic diversity, segregation, neighborhood change, involuntary mobility (displacement), local attachment, and the residential circumstances associated with wealth and affluence. He also has a career-long interest in urban homelessness.

Michael J.R. Martin is pursuing a PhD in Sociology and Demography at The Pennsylvania State University. He studies racial-ethnic diversity, segregation, and spatial analytic methods, particularly spatial clustering in transitions over time. In addition to being a graduate student, Michael works for the United States Census Bureau as a statistician, investigating computer and Internet availability and aspects of the digital divide.

\section{References}

Alba R \& Nee V (2003). Remaking the American mainstream: Assimilation and contemporary immigration. Cambridge, MA: Harvard University Press. 
Alberts HC (2006). The multiple transformations of Miami In Smith HA \& Furuseth OJ (Eds.), Latinos in the new south: Transformations of place (pp. 135-151). Burlington, VT: Ashgate.

Arreola DD (Ed.). (2004a). Hispanic spaces, Latino places: Community and cultural diversity in contemporary America. Austin, TX: University of Texas Press.

Arreola DD (2004b). Hispanic American legacy, Latino American diaspora In Arreola DD (Ed.), Hispanic spaces, Latino places: Community and cultural diversity in contemporary America (pp. 13-35). Austin, TX: University of Texas Press.

Bartel AP, \& Koch MJ (1991). Internal migration of U.S. immigrants In Abowd JM \& Freeman RB (Eds.), Immigration, trade, and the labor market (pp. 121-134). Chicago: University of Chicago Press.

Bean FD, \& Stevens G (2003). America's newcomers and the dynamics of diversity. New York: Russell Sage Foundation.

Clark WAV (2003). Immigrants and the American dream: Remaking the middle class. New York: Guilford.

Cornell S, \& Hartmann D (1998). Ethnicity and race: Making identities in a changing world. Thousand Oaks, CA: Pine Forge.

DeFina R, \& Hannon L (2009). Diversity, racial threat, and metropolitan housing segregation. Social Forces, 88, 373-394.

Dondero M, \& Muller C (2012). School stratification in new and established Latino destinations. Social Forces, 91, 477-502.

Durand J, Telles E, \& Flashman J (2006). The demographic foundations of the Latino population In Tienda M \& Mitchell F (Eds.), Hispanics and the future of America (pp. 66-99). Washington, DC: National Academies Press.

Ellis M, \& Goodwin-White J (2006). 1.5 generation internal migration in the U.S.: Dispersion from states of immigration? International Migration Review, 40, 899-926.

Ellis M, Wright R, \& Townley M 2016 State-scale immigration enforcement and Latino interstate migration in the United States. Annals of the American Association of Geographers, 106, 891908.

Ennis SR, Rios-Vargas M, \& Albert NG (2011). The Hispanic population: 20102010 Census Briefs, C2010BR-4. Washington, DC: U.S. Census Bureau Accessed at https://www.census.gov/prod/ cen2010/briefs/c2010br-04.pdf

Fischer MJ, \& Tienda M (2006). Redrawing spatial color lines: Hispanic metropolitan dispersal, segregation, and economic opportunity In Tienda M \& Mitchell F (Eds.), Hispanics and the future of America (pp. 100-137). Washington, DC: National Academies Press.

Flippen CA, \& Parrado EA (2012). Forging Hispanic communities in new destinations: A case study of Durham, North Carolina. City \& Community, 11, 1-30. [PubMed: 24482612]

Foley N (2014). Mexicans in the making of America. Cambridge, MA: Belknap Press of Harvard University Press.

Foner N (Ed.). (2013). One out of three: Immigrant New York in the twenty-first century. New York: Columbia University Press.

Frey WH (2015). Diversity explosion: How new racial demographics are remaking America. Washington, DC: Brookings Institution Press.

Frey WH, \& Liaw K (1999). Internal migration of foreign-born Latinos and Asians: Are they assimilating geographically? In Pandit K \& Davies Withers S (Eds.), Migration and restructuring in the United States: A geographic perspective (pp. 212-230). Lanham, MD: Rowman \& Littlefield.

Frey WH, Wilson JH, Berube A, \& Singer A (2006). Tracking American trends in the twenty-first century: A field guide to the new metropolitan and micropolitan definitions In Berube A, Katz B, \& Lang RE (Eds.), Redefining Urban and Suburban America: Evidence from Census 2000, Vol. 3 (pp. 191-234). Washington, DC: Brookings Institution Press.

Funkhouser E (2000). Changes in the geographic concentration and location of residence of immigrants. International Migration Review, 34, 489-510.

Hall M (2009). Interstate migration, spatial assimilation, and the incorporation of U.S. immigrants. Population, Space and Place, 15, 57-77. 
Hall M (2013). Residential integration on the new frontier: Immigrant segregation in established and new destinations. Demography, 50, 1873-1896. [PubMed: 23192394]

Hamilton N, \& Chinchilla NS (2011). Seeking community in a global city: Guatemalans and Salvadorans in Los Angeles. Philadelphia: Temple University Press.

Innis-Jimenez M (2013). Steel barrio: The great Mexican migration to south Chicago, 1915-1940. New York: New York University Press.

Jacobs J (1989). Long-term trends in occupational segregation by sex. American Journal of Sociology, $95,160-173$.

Johnson KM, \& Lichter DT (2008). Natural increase: A new source of population growth in emerging Hispanic destinations. Population and Development Review, 34, 327-346.

Johnson KM, \& Lichter DT (2016). Diverging demography: Hispanic and non-Hispanic contributions to U.S. population redistribution and diversity. Population Research and Policy Review, 35, 705725.

Jones RC (Ed.). (2008). Immigrants outside megalopolis: Ethnic transformation in the heartland. Lanham, MD: Lexington.

Kasinitz P, Mollenkopf JH, Waters MC, \& Holdaway J (2008). Inheriting the city: The children of immigrants come of age. New York: Russell Sage Foundation.

Kritz MM, \& Gurak DT (2015). U.S. immigrants in dispersed and traditional settlements: National origin heterogeneity. International Migration Review, 49, 106-141.

Kritz MM, Gurak DT, \& Lee M (2011). Will they stay? Foreign-born out-migration from new U.S. destinations. Population Research and Policy Review, 30, 537-557. [PubMed: 22923857]

Landale NS, Oropesa RS, \& Bradatan C (2006). Hispanic families in the United States: Family structure and process in an era of family change In Tienda M \& Mitchell F (Eds.), Hispanics and the future of America (pp. 138-178). Washington, DC: National Academies Press.

Laurence J (2014). Reconciling the contact and threat hypotheses: Doe racial ethnic diversity strengthen or weaken community inter-ethnic relations? Ethnic and Racial Studies, 37, 1328-1349.

Lee BA, Iceland J, \& Farrell CR (2014). Is ethnoracial residential integration on the rise? Evidence for metropolitan and micropolitan America since 1980 In Logan JR (Ed.), Diversity and disparities: America enters a new century (pp. 415-456). New York: Russell Sage Foundation.

Lee BA, Iceland J, \& Sharp G (2012). Racial and ethnic diversity goes local: Charting change in American communities over three decades US2010 Project. New York: Russell Sage Foundation Accessed at http://www.russellsage.org/research/reports/racial-ethnic-diversity.

Lee BA, Martin MJR, \& Hall M (2017). Solamente Mexicanos? Patterns and sources of Hispanic diversity in U.S. metropolitan areas. Social Science Research 68(11):117-31. [PubMed: 29108591]

Lichter DT (2012). Immigration and the new racial diversity in rural America. Rural Sociology, 77, $3-$ 35. [PubMed: 26478602]

Lichter DT (2013). Integration or fragmentation? Racial diversity and the American future. Demography, 50, 359-391. [PubMed: 23440733]

Lichter DT, \& Johnson KM (2009). Immigrant gateways and Hispanic migration to new destinations. International Migration Review, 43, 496-518.

Lichter DT, Parisi D, Taquino MC, \& Grice SM (2010). Residential segregation in new Hispanic destinations: Cities, suburbs, and rural communities compared. Social Science Research, 39, 215230 .

Lieberson S, \& Waters MC (1988). From many strands: Ethnic and racial groups in contemporary America. New York: Russell Sage Foundation.

Light I (2006). Deflecting immigration: Networks, markets, and regulation in Los Angeles. New York: Russell Sage Foundation.

Logan JR (2001). The new Latinos: Who they are, where they are. Lewis Mumford Center for Comparative Urban and Regional Research Accessed at http://www.s4.brown.edu/cen2000/ HispanicPop/HspReport/MumfordReport.pdf. 
Logan JR, \& Turner RN (2013). Hispanics in the United States: Not only Mexicans US2010 Project Research Brief. New York: Russell Sage Foundation Accessed at http://www.russellsage.org/ research/reports/hispanics-segregation.

Lopez G (2015). Hispanics of Colombian/Cuban/Guatemalan origin in the United States, 2013 Hispanic Trends Statistical Profiles, Pew Research Center Accessed at http:// www.pewhispanic.org/author/glopez/.

Marrow HB (2011). New destination dreaming: Immigration, race, and legal status in the rural South. Stanford, CA: Stanford University Press.

Martin E (2002). Questionnaire effects on reporting of race and Hispanic origin: Results of a replication of the 1990 mail short form in Census 2000 Census 2000 TXE Program Report, U.S. Census Bureau Accessed at https://www.census.gov/pred/www.rpts/AQE\%20R\&HO\%20Final $\% 20$ Report.pdf.

Massey DS (Ed.). (2008). New faces in new places: The changing geography of American immigration. New York: Russell Sage Foundation.

Massey DS, \& Capoferro C (2008). The geographic diversification of American immigration In Massey DS (Ed.), New faces in new places: The changing geography of American immigration (pp. 25-50). New York: Russell Sage Foundation.

Massey DS, \& Denton NA (1988). The dimensions of residential segregation. Social Forces, 67, 281315.

McClain PD, Carter NM, DeFrancesco Soto VM, Lyle ML, Grynaviski JD, Nunnally SC, Scotto TJ, Kendrick JA, Lackey GF, \& Cotton KD (2006). Racial distancing in a southern city: Latino immigrants' views of Black Americans. Journal of Politics, 68, 571-584.

McConnell ED (2008). The U.S. destinations of contemporary Mexican immigrants. International Migration Review, 42, 767-802.

McDermott M (2011). Black attitudes and Latino immigrants in South Carolina In Telles E, Sawyer MQ, \& Rivera-Salgado G (Eds.), Just neighbors? Research on African American and Latino relations in the United States (pp. 242-263). New York: Russell Sage Foundation.

NALEO Educational Fund. 2016 National directory of Latino elected officials. Los Angeles: NALEO Educational Fund Accessed at https://d3n8a8pro7vhmx.cloudfront.net/naleo/pages/188/ attachments/original/1474060157/2016_National_Directory_of_Latino_Elected_Officials.pdf

Ochoa GL 2004 Becoming neighbors in a Mexican-American community: Power, conflict, and solidarity. Austin, TX: University of Texas Press.

Oropesa RS, \& Jensen L (2010). Dominican immigrants and discrimination in a new destination: The case of Reading, Pennsylvania. City \& Community, 9, 274-298. [PubMed: 25506273]

Parisi D, Lichter DT, \& Taquino MC (2015). The buffering hypothesis: Growing diversity and declining Black-White segregation in America's cities, suburbs, and small towns? Sociological Science, 2, 125-157.

Park J, \& Iceland J (2011). Residential segregation in metropolitan established immigrant gateways and new destinations, 1990-2010. Social Science Research, 40, 811-821. [PubMed: 25589795]

Parrado EA (2012). Immigration enforcement policies, the economic recession, and the size of local Mexican immigrant populations. Annals of the American Academy of Political and Social Science, 641, 16-37.

Portes A, \& Rumbaut RG (2006). Immigrant America: A portrait (3rd Ed.). Berkeley, CA: University of California Press.

Portes A, \& Zhou M (1993). The new second generation: Segmented assimilation and its variants. Annals of the American Academy of Political and Social Science, 530, 74-96.

Putnam RD (2007). E pluribus unum: Diversity and community in the twenty-first century. Scandinavian Political Studies, 30, 137-174.

Rumbaut R (2006). The making of a people In Tienda M \& Mitchell F (Eds.), Hispanics and the future of America (pp. 16-65). Washington, DC: National Academies Press.

Sabagh G, \& Bozorgmehr M (2003). From 'give me your poor' to 'save our state': New York and Los Angeles as immigrant cities and regions In Halle D (Ed.), New York and Los Angeles: Politics, society, and culture (pp. 99-123). Chicago: University of Chicago Press.

Saenz R, \& Morales MC (2015). Latinos in the United States. Cambridge, UK: Polity Press. 
Sharp G, \& Lee BA (2017). New faces in rural places: Patterns and sources of nonmetropolitan ethnoracial diversity since 1990. Rural Sociology, 82, 411-443. [PubMed: 29556111]

Singer A (2005). The rise of new immigrant gateways: Historical flows, recent settlement trends In Berube A, Katz B, \& Lang RE (Eds.), Redefining urban and suburban America: Evidence from census 2000, vol. II (pp. 42-86). Washington, DC: Brookings Institution Press.

Singer A, Hardwick SW, \& Brettell CB (Eds.). (2008). Twenty-first century gateways: Immigrant incorporation in suburban America. Washington, DC: Brookings Institution Press.

Stepler R, \& Chavez MH (2016). U.S. Latino population growth and dispersion has slowed since onset of the Great Recession. Pew Research Center Accessed at http://www.Pewhispanic.org/ 2016/09/08/latino-population-growth-and-dispersion-has-slowed-since-the-onset-of-the-greatrecession/.

Suro R (2002). Counting the 'other Hispanics': How many Colombians, Dominicans, Ecuadorians, Guatemalans, and Salvadorans are there in the United States? Pew Hispanic Center. Accessed at http://www.pewhispanic.org/files/reports/8.pdf.

Suro R, \& Singer A (2003). Changing patterns of Latino growth in metropolitan America In Katz B \& Lang RE (Eds.), Redefining urban and suburban America: Evidence from census 2000, vol. I (pp. 181-210). Washington, DC: Brookings Institution Press.

Telles E, Sawyer MQ, \& Rivera-Salgado G (Eds.), Just neighbors? Research on African American and Latino relations in the United States. New York: Russell Sage Foundation.

Tienda M, \& Fuentes N (2014). Hispanics in metropolitan America: New realities and old debates. Annual Review of Sociology, 40, 499-520.

Tienda M, \& Sanchez SM (2013). Latin American immigration to the United States. Daedalus, 142, 48-64. [PubMed: 26560092]

Tran VC, \& Valdez NM (2017). Second-generation decline or advantage? Latino assimilation in the aftermath of the great recession. International Migration Review, 51, 155-190.

Vallejo J (2012). Barrios to burbs: The making of the Mexican American middle class. Stanford, CA: Stanford University Press.

van der Meer T, \& Tolsma J (2014). Ethnic diversity and its effects on social cohesion. Annual Review of Sociology, 40, 459-478.

Varsanyi MW (Ed.). (2010). Taking local control: Immigration policy activism in U.S. cities and states. Stanford, CA: Stanford University Press.

Walker KE, \& Leitner H (2011). The variegated landscape of local immigration policies in the United States. Urban Geography, 32, 156-178.

Waters MC, \& Jimenez TR (2005). Assessing immigrant assimilation: New empirical and theoretical challenges. Annual Review of Sociology, 31, 105-125.

Waters MC, \& Pineau MG (Eds.). (2015). The integration of immigrants into American society. Washington, DC: National Academies Press.

White MJ (1986). Segregation and diversity measures in population distribution. Population Index, 52, 198-221. [PubMed: 12340704]

White MJ, \& Glick JE (2009) Achieving anew: How new immigrants do in American schools, jobs, and neighborhoods. New York: Russell Sage Foundation.

Wilson SG, Plane DA, Mackun PJ, Fischetti TR, \& Goworowska J (2012). Patterns of metropolitan and micropolitan change: 2000 to 20102010 Census Special Reports, C2010SR-01. Washington, DC: U.S. Census Bureau.

Winders J (2013). Nashville in the new millennium: Immigrant settlement, urban transformation, and social belonging. New York: Russell Sage Foundation.

Wortham S, Murillo EJ Jr., \& Hamann ET (2002). Education in the new Latino diaspora: Policy and the politics of identity. Westport, CT: Ablex.

Wright RA, Ellis M, Holloway SR, \& Wong S (2014). Patterns of racial diversity and segregation in the United States, 1990-2010. Professional Geographer, 66, 173-182. [PubMed: 25083001]

Zuniga V, \& Hernandez-Leon R (Eds.). (2005). New destinations: Mexican immigration in the United States. New York: Russell Sage Found 


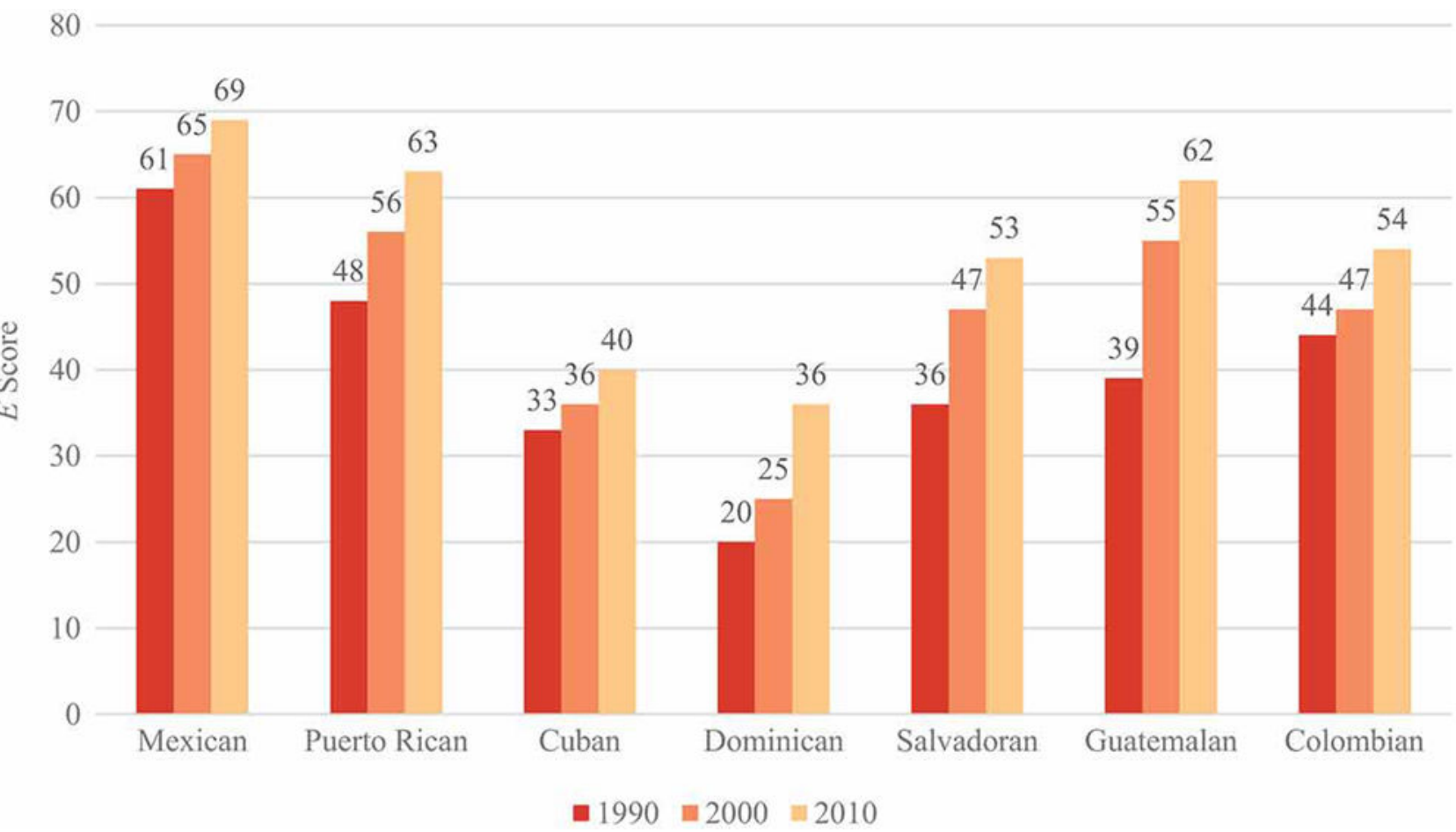

Figure 1.

Dispersion of Origin Groups across Metro Areas, 1990-2010. 


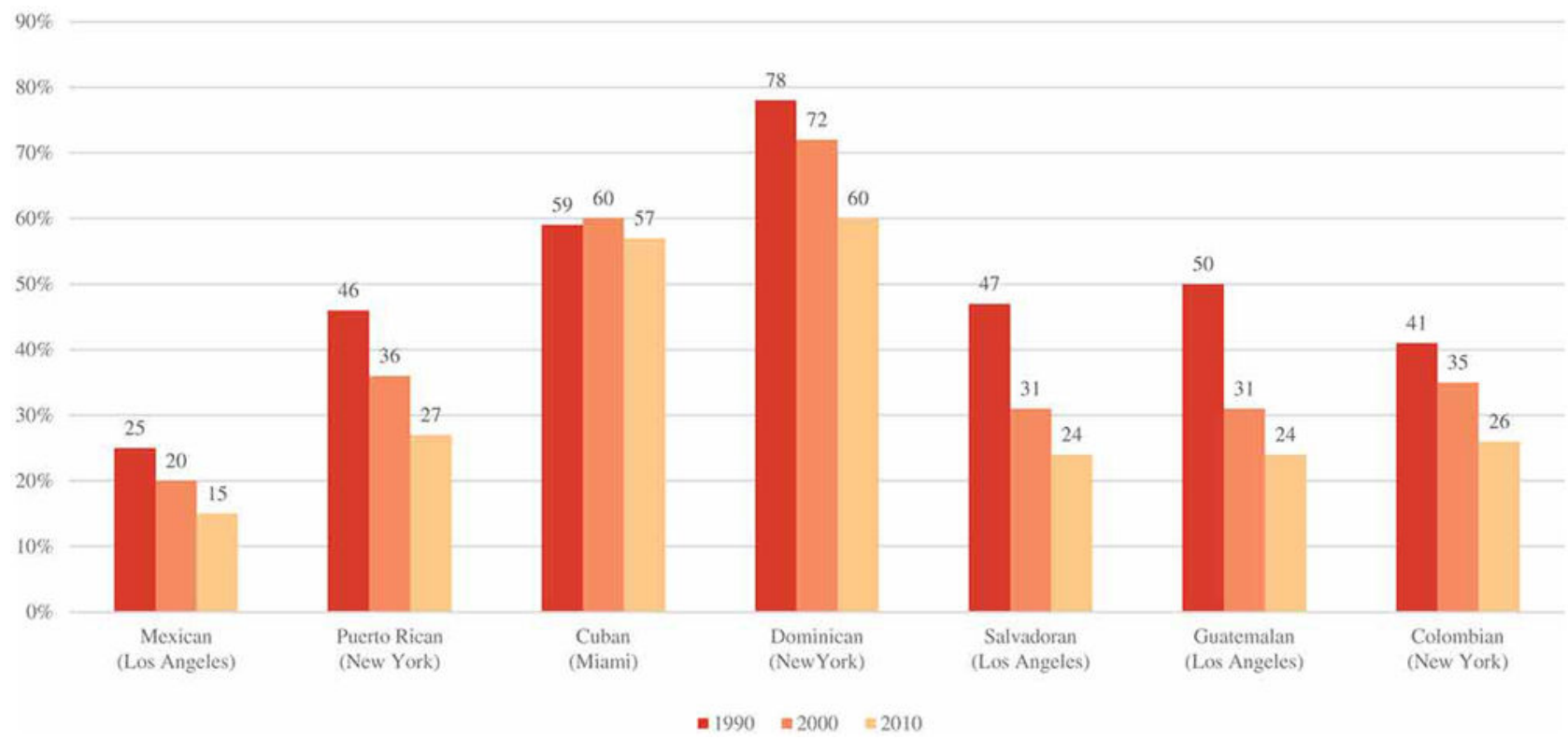

Figure 2.

Percentage of Origin Group in Principal Metro Gateway, 1990-2010. 


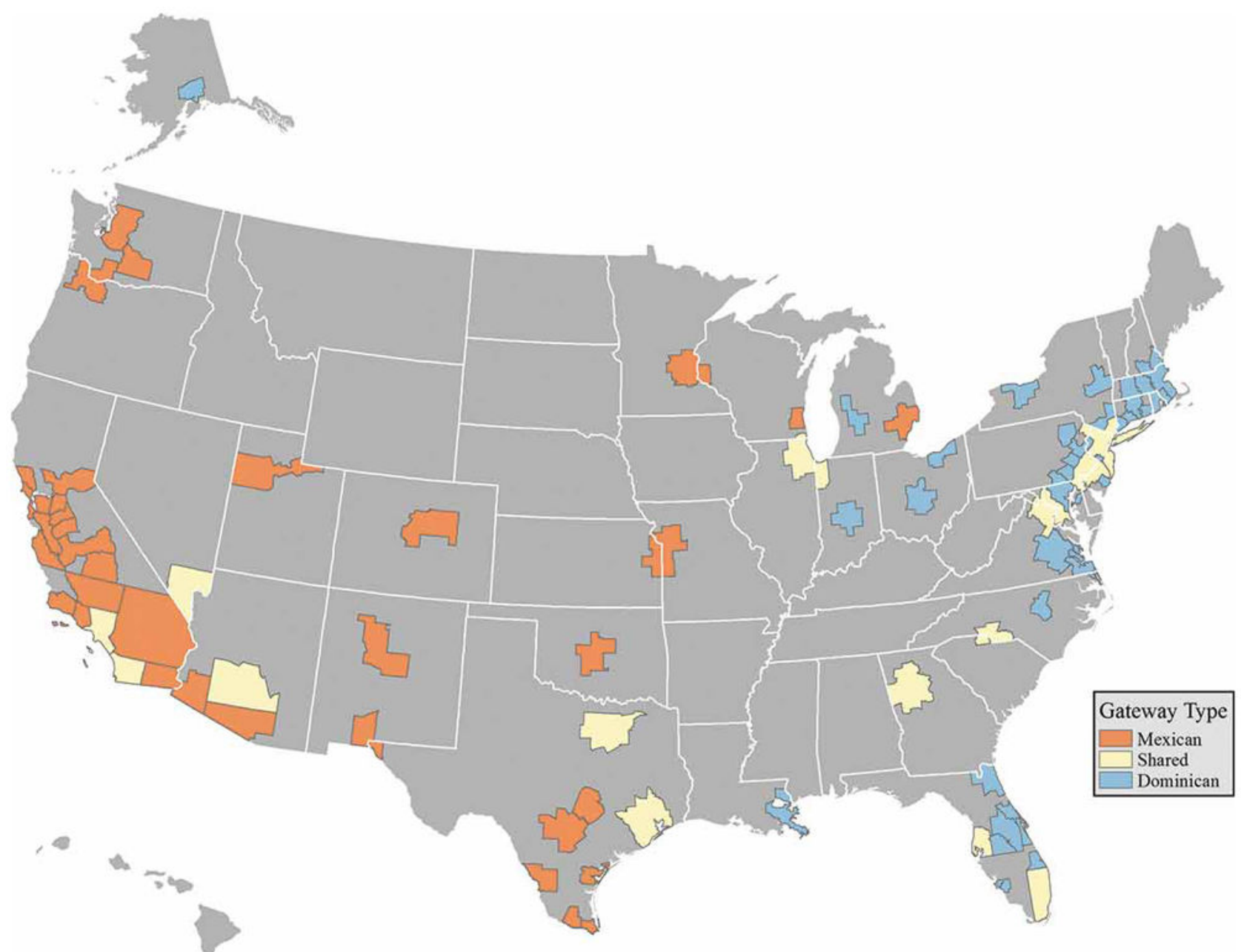

Figure 3.

Primary gateways of Mexican and Dominican origin groups, 2010. 


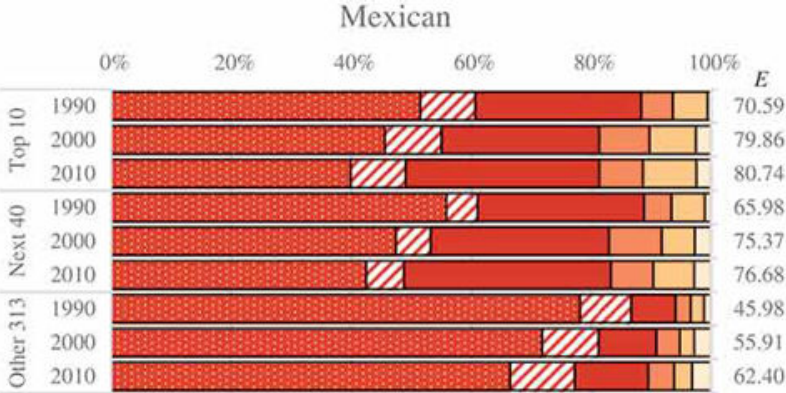

Cuban

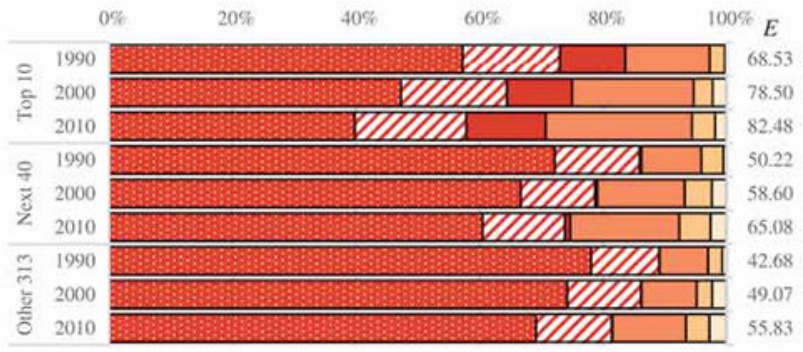

Guatemalan

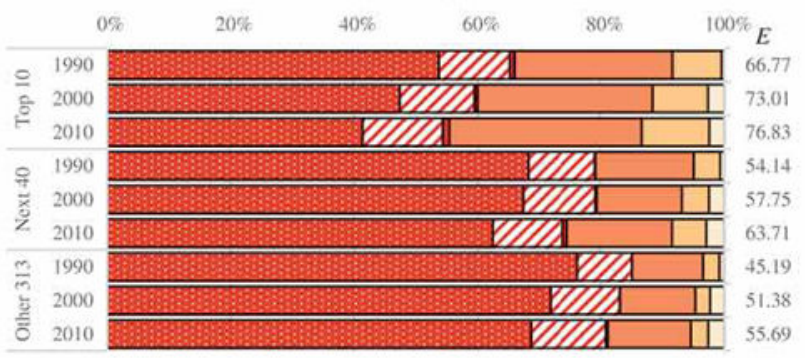

Colombian

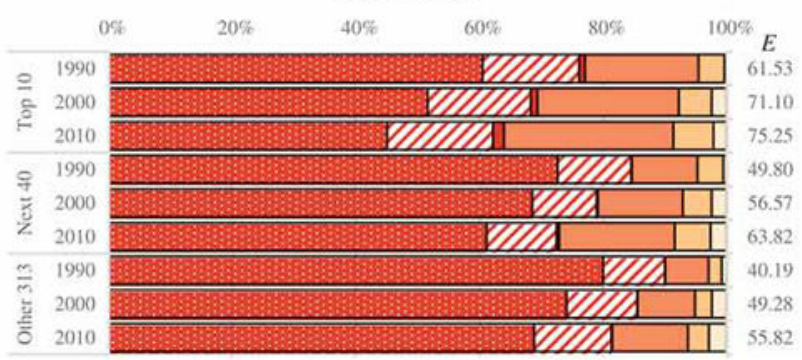

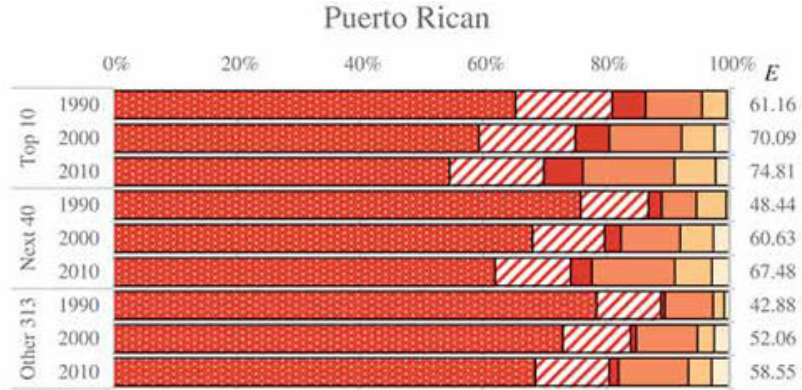

Dominican

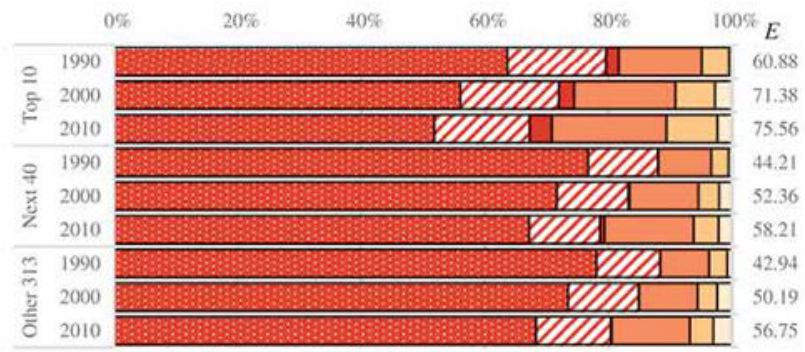

Salvadoran

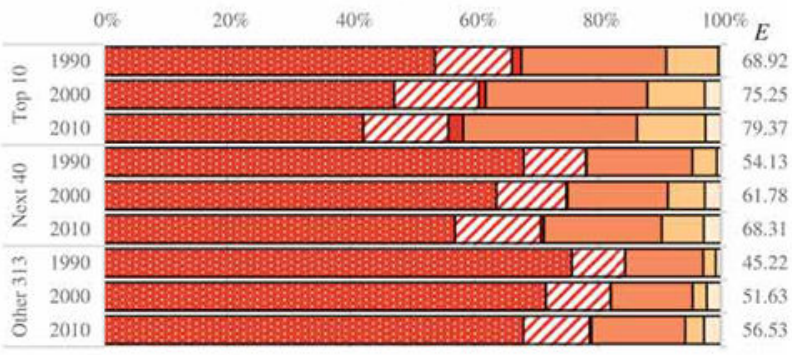

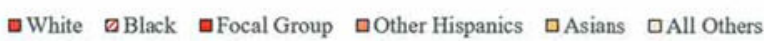

Figure 4.

Origin Group Exposure to Ethnoracial Diversity and Composition in Primary Gateways, Secondary Destinations, and Other Destinations, 1990-2010. 
Table 1.

Percentage of Origin Group in Primary Gateways, Secondary Destinations, and Other Destinations, 1990-2010

\begin{tabular}{|c|c|c|c|}
\hline \multirow{2}{*}{$\begin{array}{l}\text { Group } \\
\text { Metro Area }\end{array}$} & \multicolumn{3}{|c|}{$\%$ of All Metro Group Members } \\
\hline & 1990 & 2000 & 2010 \\
\hline \multicolumn{4}{|l|}{ Mexican } \\
\hline Primary Gateways (10) & 60.23 & 55.84 & 51.30 \\
\hline Secondary Destinations (40) & 30.18 & 27.71 & 32.26 \\
\hline Other Destinations (313) & 9.58 & 16.45 & 16.44 \\
\hline Group Populations (in 000's) & 12,201 & 18,895 & 28,956 \\
\hline \multicolumn{4}{|l|}{ Puerto Rican } \\
\hline Primary Gateways (10) & 72.97 & 66.46 & 59.11 \\
\hline Secondary Destinations (40) & 19.88 & 20.81 & 27.47 \\
\hline Other Destinations (313) & 7.15 & 12.74 & 13.41 \\
\hline Group Populations (in 000's) & 2,579 & 3,284 & 4,414 \\
\hline \multicolumn{4}{|l|}{ Cuban } \\
\hline Primary Gateways (10) & 87.93 & 84.22 & 79.88 \\
\hline Secondary Destinations (40) & 7.98 & 8.77 & 13.23 \\
\hline Other Destinations (313) & 4.09 & 7.00 & 6.89 \\
\hline Group Populations (in 000's) & 1,053 & 1,209 & 1,733 \\
\hline \multicolumn{4}{|l|}{ Dominican } \\
\hline Primary Gateways (10) & 94.33 & 91.69 & 84.81 \\
\hline Secondary Destinations (40) & 3.94 & 5.15 & 10.82 \\
\hline Other Destinations (313) & 1.73 & 3.15 & 4.37 \\
\hline Group Populations (in 000's) & 517 & 758 & 1,396 \\
\hline \multicolumn{4}{|l|}{ Salvadoran } \\
\hline Primary Gateways (10) & 90.85 & 83.33 & 76.28 \\
\hline Secondary Destinations (40) & 6.97 & 10.52 & 16.26 \\
\hline Other Destinations (313) & 2.19 & 6.15 & 7.46 \\
\hline Group Populations (in 000's) & 560 & 642 & 1,604 \\
\hline \multicolumn{4}{|l|}{ Guatemalan } \\
\hline Primary Gateways (10) & 86.27 & 71.82 & 63.52 \\
\hline Secondary Destinations (40) & 10.46 & 17.46 & 23.71 \\
\hline Other Destinations (313) & 3.27 & 10.72 & 12.77 \\
\hline Group Populations (in 000's) & 266 & 355 & 977 \\
\hline \multicolumn{4}{|l|}{ Colombian } \\
\hline Primary Gateways (10) & 80.60 & 78.06 & 71.69 \\
\hline Secondary Destinations (40) & 13.00 & 13.15 & 18.73 \\
\hline Other Destinations (313) & 6.41 & 8.79 & 9.58 \\
\hline Group Populations (in 000's) & 372 & 462 & 888 \\
\hline
\end{tabular}

J Urban Aff. Author manuscript; available in PMC 2020 April 07. 
Table 2.

Dissimilarity of Origin Group Distributions across Metro Areas, 1990-2010

\begin{tabular}{|c|c|c|c|c|c|c|c|}
\hline $\begin{array}{l}\text { Year } \\
\text { Group }\end{array}$ & Mexican & $\begin{array}{l}\text { Puerto } \\
\text { Rican }\end{array}$ & Cuban & Dominican & Guatemalan & Salvadoran & Mean D \\
\hline \multicolumn{8}{|l|}{1990} \\
\hline Mexican & - & & & & & & 0.73 \\
\hline Puerto Rican & 0.81 & - & & & & & 0.58 \\
\hline Cuban & 0.83 & 0.63 & - & & & & 0.67 \\
\hline Dominican & 0.94 & 0.37 & 0.71 & - & & & 0.67 \\
\hline Guatemalan & 0.52 & 0.64 & 0.68 & 0.75 & - & & 0.56 \\
\hline Salvadoran & 0.54 & 0.74 & 0.72 & 0.80 & 0.19 & - & 0.60 \\
\hline Colombian & 0.75 & 0.29 & 0.44 & 0.41 & 0.57 & 0.63 & 0.52 \\
\hline \multicolumn{8}{|l|}{2000} \\
\hline Mexican & - & & & & & & 0.70 \\
\hline Puerto Rican & 0.77 & - & & & & & 0.55 \\
\hline Cuban & 0.79 & 0.62 & - & & & & 0.64 \\
\hline Dominican & 0.92 & 0.42 & 0.72 & - & & & 0.65 \\
\hline Guatemalan & 0.46 & 0.57 & 0.62 & 0.69 & - & & 0.51 \\
\hline Salvadoran & 0.50 & 0.65 & 0.69 & 0.73 & 0.24 & - & 0.57 \\
\hline Colombian & 0.74 & 0.29 & 0.41 & 0.42 & 0.51 & 0.58 & 0.49 \\
\hline \multicolumn{8}{|l|}{2010} \\
\hline Mexican & - & & & & & & 0.67 \\
\hline Puerto Rican & 0.74 & - & & & & & 0.54 \\
\hline Cuban & 0.77 & 0.60 & - & & & & 0.63 \\
\hline Dominican & 0.88 & 0.42 & 0.69 & - & & & 0.63 \\
\hline Guatemalan & 0.46 & 0.53 & 0.62 & 0.65 & - & & 0.49 \\
\hline Salvadoran & 0.48 & 0.63 & 0.69 & 0.72 & 0.24 & - & 0.55 \\
\hline Colombian & 0.69 & 0.31 & 0.39 & 0.45 & 0.45 & 0.54 & 0.47 \\
\hline
\end{tabular}

J Urban Aff. Author manuscript; available in PMC 2020 April 07. 